\title{
Effect of sucralfate on aspirin induced mucosal injury and impaired haemostasis in humans
}

\author{
N Hudson, F E Murray, A T Cole, B Filipowicz, C J Hawkey
}

\begin{abstract}
Background-Sucralfate does not have potent anti-ulcerogenic actions in users of non-steroidal anti-inflammatory drugs (NSAIDs). However, sucralfate may influence intragastric haemostasis favourably. Aim-To investigate separately the effects of sucralfate on acute gastric and duodenal injury and on changes in intragastric bleeding induced by aspirin.

Method-On three occasions, 24 healthy volunteers received three days' treatment with aspirin $900 \mathrm{mg}$ twice daily together with placebo, sucralfate $2 \mathrm{~g}$ twice daily or sucralfate $1 \mathrm{~g}$ four times daily. Injury was assessed endoscopically and bleeding by spontaneous and biopsy induced bleeding intragastric washings. Ex vivo prostaglandin $E_{2}\left(P_{G E}\right)$ synthesis and serum thromboxane were measured by using radioimmunoassay.

Results-Aspirin significantly inhibited ex vivo gastric mucosal $\mathbf{P G E}_{2}$ synthesis, reduced serum thromboxane, caused gastric erosions, and increased spontaneous and biopsy induced bleeding. Sucralfate had no significant effects on endoscopic injury but sucralfate $1 \mathrm{~g}$ four times daily significantly reduced spontaneous and biopsy induced bleeding. Similar trends were seen with sucralfate $2 \mathrm{~g}$ twice daily but the results were less consistent.

Conclusion-Sucralfate does not affect aspirin induced acute gastric mucosal injury but reduces aspirin associated intragastric bleeding.

(Gut 1997; 41: 19-23)
\end{abstract}

Keywords: aspirin; non-steroidal anti-inflammatory drug; sucralfate; ulcer; haemostasis; protection

Division of

Gastroenterology,

University Hospital,

Nottingham NG7 2UH

N Hudson

B Filipowicz

C J Hawkey

Beaumont Hospital, Dublin 9, Ireland

F E Murray

Department of Gastroenterology, Derby City Hospital,

Uttoxeter Road, Derby

A T Cole

Correspondence to:

Professor C J Hawkey,

Division of Gastroenterology,

University Hospital,

Nottingham NG7 2UH.

Accepted for publication

28 November 1996
Optimal prophylaxis of non-steroidal antiinflammatory drug (NSAID) induced ulcers and their complications remains elusive. ${ }^{1-3}$ When patients present with haematemesis and melaena, the main complication of NSAID associated ulcers, this may arise because the drugs induce ulcers or because they induce bleeding in pre-existing ulcers. ${ }^{145}$ We have developed methods permitting separate assessment of the erosive and anti-haemostatic effects of NSAIDs in the human gastric mucosa. ${ }^{6}$ Sucralfate is an effective ulcer healing agent with cytoprotective properties. ${ }^{7-9}$ Nevertheless, its ability to prevent NSAID associated gastric ulcers diagnosed endoscopically is limited. ${ }^{10}$ Sucralfate, however, is capable of improving intragastric haemostasis, particularly by inhibiting fibrinolytic and peptic activity. ${ }^{11-13}$ This action may contribute to sucralfate's established well known ability to prevent stress induced gastric bleeding. ${ }^{14-17}$

As, in these circumstances, sucralfate's predominant intragastric action may be on haemostasis ${ }^{11-13}$ rather than ulceration, we investigated its effects on acute aspirin induced intragastric mucosal erosions, mucosal damage and bleeding to see whether these effects could be differentiated.

\section{Methods}

This was a double blind, placebo controlled, crossover comparison with randomisation according to Latin square design. Each treatment period was of three days duration with a washout period between treatments of 11 days. Our previous studies have shown that erosions heal within two to three days ${ }^{6}$ and an 11 day washout period is associated with no carry over effects attributable to the previous treatment. ${ }^{18}$ Each subject received, under blinded, randomised conditions, each of the following dosage regimens: aspirin $900 \mathrm{mg}$ twice daily with placebo; aspirin $900 \mathrm{mg}$ twice daily with sucralfate $2 \mathrm{~g}$ twice daily; aspirin $900 \mathrm{mg}$ twice daily with sucralfate $1 \mathrm{~g}$ four times daily.

SUBJECTS

Twenty four healthy volunteers were studied. The main exclusion criteria included hypersensitivity to aspirin, presence or history of peptic ulceration or significant dyspepsia, history of easy bruising or bleeding, bleeding abnormality detected during initial screening, anaemia, history of asthma, lactation, pregnancy, or unacceptable contraception.

STUDY PROCEDURES

Subjects underwent a medical examination, with haematological/biochemical screening up to two weeks before the start of the study. During the study the following procedures were done before dosing and on day 3 of each dosing period.

\section{GASTRIC MICROBLEEDING ${ }^{18} 19$}

Fasted subjects swallowed an orogastric tube at approximately 0800 hours of each study day, 90 minutes after taking the last dose of aspirin with water. One hundred millilitres of water was introduced through the orogastric tube, rinsed around the stomach (see later) and then drained. This procedure was repeated three times. Three 10 minute collection periods then commenced and at the end of each period the 
stomach was washed with $100 \mathrm{ml}$ water. Phenol red was used to measure recovery and the stomach was rinsed twice after each wash to remove phenol red before the next collection period. Whenever liquids were introduced into the stomach, each volunteer performed a series of manoeuvres designed to ensure contact of the liquid with all parts of the stomach. Blood in the gastric washings was measured spectrophotometrically using the orthotolidine reaction, and corrected for phenol red recovery.

ENDOSCOPIC ASSESSMENT OF INIURY

Immediately after gastric washing for microbleeding was complete, the orogastric tube was removed and the volunteers underwent unsedated endoscopy with a $7.9 \mathrm{~mm}$ diameter XP endoscope. ${ }^{6}$ Erosions in the oesophagus, gastric body, gastric antrum, and duodenum were counted separately. Endoscopic assessment was performed rapidly in order to minimise the time between assessment of microbleeding and collection of washings for the assessment of biopsy induced bleeding (see later). Although four endoscopists participated in the study, each studied their own cohort of volunteers. Previous studies from our unit have, however, shown a close interindividual correlation $(r=0.85)$ in the endoscopic assessment of acute injury. ${ }^{20}$

BLEEDING PER EROSION ${ }^{6}$

This value was derived in subjects found to have erosions at endoscopy by dividing the overall rate of gastric microbleeding by the total number of erosions seen in the stomach (body and antrum aggregated).

BIOPSY INDUCED BLEEDING RATES ${ }^{6}$

At the end of the endoscopy, four mucosal biopsy specimens were taken from the greater curve at approximately $50 \mathrm{~cm}$ from the teeth using a standard $2 \mathrm{~mm}$ cup biopsy forceps. The endoscope was withdrawn and subjects were immediately intubated with a prepared orogastric tube. The gastric mucosa was washed with $100 \mathrm{ml}$ water five minutes after mucosal biopsy and again after a further five minutes. During this time subjects lay rocking on their left hand side only so that the bleeding biopsy site was selectively washed. The recovered blood was measured using the orthotolidine reaction, and corrected for spontaneous mucosal bleeding as described previously. ${ }^{6} 1819$

EICOSANOIDS

The four biopsy specimens were divided into pairs and washed in Tris buffered saline (TBS). Each pair of biopsy specimens was then vortexed in $500 \mu \mathrm{l}$ TBS for one minute at room temperature. The biopsy specimens were then removed and weighed, and the supernatant stored at $-70^{\circ} \mathrm{C}$ until assay. Prostaglandin $\mathrm{E}_{2}$ $\left(\mathrm{PGE}_{2}\right)$ in the unextracted supernatant was measured using specific radioimmuno- assays. ${ }^{61} \mathrm{PGE}_{2}$ was expressed as $\mathrm{pg} / \mathrm{mg}$ wet weight of gastric mucosa.

\section{SERUM THROMBOXANE}

This was assayed in 12 of the subjects. Immediately after endoscopy, $10 \mathrm{ml}$ blood was taken and allowed to clot for 30 minutes at $37^{\circ} \mathrm{C} .{ }^{5}$ Serum thromboxane was measured in separated serum from these samples using a radioimmunoassay. ${ }^{6}$

STATISTICS AND POWER

Analysis of variance was used to identify statistically significant differences. Bleeding values - basal microbleeding, bleeding per erosion and biopsy induced bleeding - as well as the number of lesions detected endoscopically tend to have a skewed distribution which approximates to normal after logarithmic transformation. The data were analysed in their logarithmic form. For analyses involving numbers of lesions, subjects with no detectable lesions were regarded as having 0.5 lesions to allow an analysis in this way. Based upon previous data, ${ }^{6}$ the present study was designed to have the power to detect a reduction in microbleeding from $10 \mu \mathrm{l} / 10$ minutes to 5.6 $\mu 1 / 10$ minutes $(1-\beta=0 \cdot 8)$ or $5 \cdot 1 \mu \mathrm{l} / 10$ minutes $(1-\beta=0 \cdot 9)$, based upon two-tailed testing and $\alpha=0.05$.

\section{Results}

SUBJECTS

Twenty four volunteers were enrolled into the study. Twenty three completed all study periods successfully and formed the basis of the analysis. One subject had food in the stomach preventing visualisation at the final assessment: all data from this subject were excluded from analysis.

\section{GASTRIC MUCOSAL SYNTHESIS OF} PROSTAGLANDIN $E_{2}$

There was a significant inhibition of ex vivo gastric mucosal $\mathrm{PGE}_{2}$ synthesis $(\mathrm{p}<0.001)$ when aspirin was given over the three day period (table 1). Sucralfate did not seem to attenuate this reduction in $\mathrm{PGE}_{2}$ synthesis association with aspirin. There was no significant difference in gastric mucosal $\mathrm{PGE}_{2}$ synthesis rates between the three treatment arms.

TABLE 1 Gastric mucosal synthesis of prostaglandin $E_{2}$ before and after treatment with aspirin and aspirin plus sucralfate

\begin{tabular}{lll}
\hline & \multicolumn{2}{l}{ Prostaglandin $E_{2}(p g / m g)$} \\
\cline { 2 - 3 } & Baseline & Final \\
\hline Aspirin & $22 \cdot 9(15 \cdot 9-37 \cdot 9)$ & $3 \cdot 2^{\star \star \star}(1 \cdot 6-6 \cdot 2)$ \\
$\begin{array}{c}\text { Aspirin+sucralfate } \\
\quad(1 \text { g qid) }\end{array}$ & $17 \cdot 8(11 \cdot 5-27 \cdot 5)$ & $3 \cdot 7^{\star \star \star}(2 \cdot 0-7 \cdot 0)$ \\
$\begin{array}{c}\text { Aspirin+sucralfate } \\
(2 \text { g bid) }\end{array}$ & $14 \cdot 1(9 \cdot 0-19 \cdot 8)$ & $4 \cdot 0^{\star \star \star}(2 \cdot 3-6 \cdot 8)$ \\
\hline
\end{tabular}

$\star \star \star \mathrm{p}<0.001$ compared with baseline. qid=for times a day; bid=twice a day. 
SERUM THROMBOXANE

These changes in mucosal $\mathrm{PGE}_{2}$ synthesis were reflected by similar changes in the serum thromboxane concentrations (table 2). Thus, at baseline before ingestion of aspirin serum thromboxane was $9 \cdot 1(6 \cdot 8-12 \cdot 2) \mathrm{ng} / \mathrm{ml}$ and fell to essentially unrecordable concentrations after treatment with aspirin or placebo $(p<0.001)$. Co-administration of sucralfate did not affect this reduction in serum thromboxane.

\section{MUCOSAL EROSIONS}

Gastric erosions

None of the subjects had any erosions before any of the treatment periods. After three days of aspirin treatment this rose significantly to $5.3(2.9-9 \cdot 4)$ erosions throughout the stomach $(\mathrm{p}<0.001$; table 3$)$. Sucralfate did not significantly affect the number of erosions after aspirin treatment. Likewise, the distribution between antrum and body was not affected by sucralfate treatment.

\section{Duodenal erosions}

Duodenal damage with all three regimens was infrequent. There was no significant difference in the number of erosions in the duodenum when aspirin was co-administered with either sucralfate $1 \mathrm{~g}$ four times daily or $2 \mathrm{~g}$ twice daily compared with aspirin with placebo.

\section{BLEEDING PARAMETERS}

\section{Validation}

In initial experiments, addition of sucralfate suspension to gastric juice in concentrations from 0 to $5 \%(\mathrm{v} / \mathrm{v})$ did not affect the quantitative assay of blood recovered ex vivo. Similarly, blood added to gastric aspirates was measured accurately and quantitatively whether sucralfate was added or not.

TABLE 2 Serum thromboxane concentrations before and after treatment with aspirin and aspirin plus sucralfate

\begin{tabular}{|c|c|c|}
\hline & \multicolumn{2}{|c|}{ Serum thromboxane $(\mathrm{ng} / \mathrm{ml})$} \\
\hline & Baseline & Final \\
\hline $\begin{array}{l}\text { Aspirin } \\
\text { Aspirin+sucralfate } \\
\quad(1 \text { g qid })\end{array}$ & $\begin{array}{l}9 \cdot 1(6 \cdot 8-12 \cdot 2) \\
8 \cdot 13(5 \cdot 8-11 \cdot 4)\end{array}$ & $\begin{array}{l}0.05^{\star \star \star}(0.05-0.05) \\
0.05^{\star \star \star}(0.05-0.05)\end{array}$ \\
\hline $\begin{array}{l}\text { Aspirin+sucralfate } \\
\text { (2 bid })\end{array}$ & $5.62(1.6-19 \cdot 8)$ & $0 \cdot 10^{\star \star \star}(0.03-0.34)$ \\
\hline
\end{tabular}

$\star \star \star \mathrm{p}<0.001$ compared with baseline. qid=four times a day; bid=twice a day

TABLE 3 Gastric mucosal erosions before and after treatment with aspirin and aspirin and sucralfate

\begin{tabular}{lll}
\hline & \multicolumn{2}{l}{ Gastric mucosal erosions } \\
\cline { 2 - 3 } & Baseline & Final \\
\hline Aspirin & 0 & $5 \cdot 3^{\star \star \star}(2 \cdot 9-9 \cdot 4)$ \\
Aspirin+sucralfate $(1 \mathrm{~g}$ qid) & 0 & $4 \cdot 2^{\star \star \star}(2 \cdot 1-8 \cdot 2)$ \\
Aspirin+sucralfate $(2 \mathrm{~g}$ bid) & 0 & $6 \cdot 9^{\star \star \star}(3 \cdot 5-13 \cdot 6)$ \\
\hline$\star \star \star$ & \\
qid=four times a day; bid=twice a day.
\end{tabular}

\section{Microbleeding}

After aspirin with placebo, the median rate of gastric microbleeding rose by a factor of 13.8 (95\% confidence interval (CI) $7 \cdot 8-24 \cdot 5$, $\mathrm{p}<0.001$ compared with baseline) from 1.6 $(1 \cdot 1-2 \cdot 3) \quad \mu l$ per 10 minutes to $24 \cdot 6$ (15.9-37.9) $\mu$ l per 10 minutes (table 4). There were also significant increases, by factors respectively of $5 \cdot 1 \quad(2 \cdot 9-9 \cdot 1)$ and $5 \cdot 8$ $(3 \cdot 2-10 \cdot 2)$ with the two sucralfate regimens. However, analysis of variance showed that there were significant differences between the three treatments for absolute bleeding values on day $3(p<0.05)$ and for the rise from baseline $(p<0.05)$. Pairwise comparisons showed that the rise with aspirin plus sucralfate $1 \mathrm{~g}$ four times daily was significantly less than for aspirin with placebo ( $\mathrm{p}=0.037$, paired $t$ test). When the absolute final value of microbleeding for aspirin plus sucralfate $1 \mathrm{~g}$ four times daily (10.5 $\mu \mathrm{l}, 95 \%$ CI 5.9-18.7 $\mu \mathrm{l}$ ) was compared with the absolute final value for aspirin (24.6 $\mu \mathrm{l}, 95 \%$ CI $15.9-37.9 \mu \mathrm{l}$ ), this was significantly reduced $(p=0.018)$. For aspirin with sucralfate $2 \mathrm{~g}$ twice daily, pairwise comparisons also showed reduced spontaneous bleeding compared with aspirin plus placebo: These differences were at borderline levels of statistical significance for the increase in microbleeding $(p=0.052)$ and the absolute final value of $12.9(6.6-25.4) \mu l$ per 10 minutes $(\mathrm{p}=0.08)$.

\section{Biopsy induced bleeding}

There was a significant increase in the amount of biopsy induced bleeding over five and 10 minutes when aspirin was administered with placebo $(p<0.01$; table 5$)$. There was no significant increase for any of these values when aspirin was administered with sucralfate $1 \mathrm{~g}$ four times daily. However, bleeding did seem

TABLE 4 Induction of microbleeding before and after treatment with aspirin and aspirin and sucralfate

\begin{tabular}{lll}
\hline & \multicolumn{2}{l}{ Microbleeding $(\mu l)$} \\
\cline { 2 - 3 } & Baseline & Final \\
\hline Aspirin & $1 \cdot 6(1 \cdot 1-2 \cdot 3)$ & $24 \cdot 6^{\star \star \star}(15 \cdot 9-37 \cdot 9)$ \\
$\begin{array}{c}\text { Aspirin+sucralfate } \\
\quad(1 \text { g qid) }\end{array}$ & $1 \cdot 7(1 \cdot 1-2 \cdot 8)$ & $10 \cdot 5^{\star \star \star} \dagger(5 \cdot 9-18 \cdot 7)$ \\
$\begin{array}{c}\text { Asprin+sucralfate } \\
(2 \text { g bid) }\end{array}$ & $2 \cdot 0(1 \cdot 2-3 \cdot 2)$ & $12 \cdot 9^{\star \star \star} \ddagger(6 \cdot 6-25 \cdot 4)$ \\
\hline
\end{tabular}

$\star \star \star \mathrm{p}<0.001$ compared with baseline

$t p=0.037$ for rise and 0.018 for final value $v$ aspirin plus

$\mathrm{tp}=0.037$
placebo.

$\neq \mathrm{p}=0.052$ for rise and 0.08 for final value $v$ aspirin plus placebo.

qid=four times a day; bid=twice a day

TABLE 5 Biopsy induced bleeding before and after treatment with aspirin and aspirin plus sucralfate

\begin{tabular}{lll}
\hline & \multicolumn{2}{l}{ Biopsy induced bleeding $(\mu l)$} \\
\cline { 2 - 3 } & Baseline & Final \\
\hline Aspirin & $74(53-104)$ & $162^{\star \star}(105-251)$ \\
Aspirin+sucralfate (1 g qid) & $93(70-125)$ & $87 \dagger(40-189)$ \\
Aspirin+sucralfate (2 g bid) & $91(56-148)$ & $263(140-493)$ \\
\hline$\star \star p<0 \cdot 01$ for increase. & & \\
$t p=0 \cdot 873$ for increase. \\
qid=four times a day; bid=twice a day.
\end{tabular}


to increase $(p=0.01)$ when aspirin was administered with sucralfate $2 \mathrm{~g}$ twice daily.

\section{Bleeding per erosion}

Twelve subjects had erosions at the final endoscopy for all treatment periods. For these subjects, it was possible to calculate a value for spontaneous microbleeding per erosion (table 6). This fell from $2.57(1.03-6 \cdot 40) \mu l$ per erosion with aspirin plus placebo to 1.02 $(0 \cdot 37-2 \cdot 81) \mu l$ per erosion when aspirin was co-administered with sucralfate $1 \mathrm{~g}$ four times daily $(p=0.065)$, and $1.05(0.46-2.36) \mu l$ per erosion when aspirin was co-administered with sucralfate $2 \mathrm{~g}$ twice daily $(\mathrm{p}=0 \cdot 072)$.

\section{Discussion}

In this study the effects of aspirin on $\mathrm{PGE}_{2}$, thromboxane, erosions, and bleeding are very similar to those observed in previous studies of similar design and duration conducted in this department. ${ }^{6}$ 18-20 These studies have established the validity of the method. They have shown that assessment of the number of erosions is reproducible between individual endoscopists. Moreover, each endoscopist studied a cohort of volunteers to improve the reproducibility of repeated measurements. Our previous studies have also shown that the washout period used in this study is sufficient for erosions to heal, for the serum thromboxane concentration to return to normal, and for intragastric bleeding to be uninfluenced by treatment order. In the present study we found that sucralfate had no significant protective effects against the development of gastric erosions, but that several of our measures of intragastric bleeding were favourably influenced. Thus, aspirin caused significant increases in microbleeding and in biopsy induced bleeding and these, along with the amount of bleeding per erosion, were significantly reduced when sucralfate $1 \mathrm{~g}$ four times daily was co-administered with aspirin. Sucralfate $2 \mathrm{~g}$ twice daily also showed a trend towards a reduction in spontaneous microbleeding and in bleeding per erosion, although these were both at borderline levels of significance. Sucralfate $2 \mathrm{~g}$ twice daily did not, however, abrogate the increase in biopsy induced bleeding seen with aspirin. The reason for this discrepancy between the two sucralfate dosing regimens is not clear. Overall, however, our results suggest that sucralfate has a direct effect on intragastric haemostasis.

Bleeding is a balance between clot formation and clot lysis. Fibrinolysis is a two stage

TABLE 6 Bleeding per erosion before and after treatment with aspirin and aspirin plus sucralfate

\begin{tabular}{lll}
\hline & \multicolumn{2}{l}{ Bleeding per erosion $(\mu l)$} \\
\cline { 2 - 3 } & Baseline & Final \\
\hline Aspirin & - & $2 \cdot 57(1 \cdot 03-6 \cdot 40)$ \\
Asprin+sucralfate $(1 \mathrm{~g}$ qid) & - & $1 \cdot 02^{\star}(0 \cdot 37-2 \cdot 81)$ \\
Aspirin+sucralfate $(2 \mathrm{~g}$ bid $)$ & - & $1 \cdot 05+(0 \cdot 46-2 \cdot 36)$ \\
\hline${ }^{*} \mathrm{p}=0.065 ; \mathrm{tp}=0.072$. & & \\
qid=four times a day; bid=twice a day.
\end{tabular}

process initiated by formation of fibrin and is evident within one to three minutes. ${ }^{22}$ Clot lysis seems to be particularly important in relation to intragastric bleeding as it is strongly activated by gastric juice via a proteolytic and a plasminogen dependent pathway. ${ }^{12}$ Sucralfate brings about profound reductions in both proteolysis and plasmin mediated fibrinolysis, ${ }^{11} 12$ and it seems likely that these actions also underlie our results. Given a one to three minute delay in activation of detectable fibrinolysis, it is also possible that suppression of biopsy induced bleeding by sucralfate would be more evident at later time points.

Sucralfate is widely used in the prophylaxis of stress ulceration in patients on intensive care units. A direct effect on intragastric bleeding rather than any primary anti-erosive effects may underlie this therapeutic efficacy. In most studies bleeding has been used as an end point rather than direct endoscopic mucosal assessment. ${ }^{14-17}$ Whether sucralfate reduces stress induced erosions compared with placebo ${ }^{16}{ }^{23}$ or $\mathrm{H}_{2}$-receptor antagonists ${ }^{24}$ is controversial with discrepancies between different studies. It is also controversial whether $\mathrm{H}_{2}$-receptor antagonists reduce stress associated bleeding by an anti-erosive effect. ${ }^{25-27}$ Thus, for both sucralfate and $\mathrm{H}_{2}$-receptor antagonists an effect on intragastric bleeding rather than on mucosal erosion may be important when used in a prophylaxis of stress associated bleeding. Whether the same applies to prophylaxis by sucralfate and $\mathrm{H}_{2}$-receptor antagonists of NSAID associated ulcers cannot be determined directly. However, this too is possible as indirect evidence suggests that $\mathrm{H}_{2}$-receptor antagonists have a greater effect on recurrence of ulcer bleeding than uncomplicated ulceration, ${ }^{45}$ implying an additional effect on haemostasis. Our data raise the possibility that sucralfate could likewise prevent NSAID associated bleeding complications, by direct effect on haemostasis, rather than an antierosive one.

Although these results were obtained in volunteers in the short term with aspirin, this approach is predictive of the behaviour of prostaglandin analogues and of acid suppressing drugs in clinical practice. In short term studies prostaglandins have proved to be protective for both the stomach and duodenum and the same is true of long term prevention of ulceration. ${ }^{12}$ Normal doses of $\mathrm{H}_{2}$-receptor antagonists, by contrast, only exert significant protection in the duodenum both in the short term studies with aspirin ${ }^{28}$ and long term studies with NSAIDs. ${ }^{329} 30$ Our data, therefore, suggest that sucralfate would not have a significant ability to prevent NSAID associated ulcers in the long term. One study which compared sucralfate with misoprostol showed little efficacy in prevention of ulcers detected endoscopically. The predictive value of the effects of sucralfate on haemostasis that we have shown is less easy to determine. However, we have shown that acid suppression specifically reduces intragastric bleeding in the short term, ${ }^{31}$ and several authors have shown that relapse with ulcer bleeding in the long 
term is reduced to a greater extent than uncomplicated relapse. ${ }^{45}$ It is possible that sucralfate could reduce the incidence of NSAID induced haematemesis and melaena without reducing the development of ulcers, although it would be a formidable proposition to demonstrate this directly.

We thank Miss Donna Hall, Miss Claire Spencer and Mrs Rosemary Dainty for preparation of the manuscript, and Chugai for their financial support and for supplying sucralfate.

1 Hawkey CJ. Non-steroidal anti-inflammatory drugs and ulcers: facts and figures multiply, but do they add up? BMf 1990; 300: 278-84.

2 Silverstein FE, Graham DY, Senior JR, Davies HW, Struthers BJ, Bittman RM, et al. Misoprostol reduces serious gastrointestinal complications in patients with
rheumatoid arthritis receiving nonsteroidal anti-inflamrheumatoid arthritis receiving nonsteroidal anti-inflam-
matory drugs - a randomized double blind placebo matory drugs - a randomized double blind place
controlled study. Ann Intern Med 1995; 123: 241-9.

3 Taha A, Hudson N, Hawkey CJ, Swannell AJ, Trye PN, Cottrell $\mathrm{J}$, et al. Famotidine for prevention of gastric and duodenal ulcers caused by nonsteroidal anti-inflammatory drugs. $N$ Engl f Med 1996; 334: 1435-9.

4 Penston JG, Wormsley KG. Nine years of maintenance treatment with ranitidine for patients with duodenal ulcer disease. Aliment Pharmacol Ther 1992; 6: 629-45.

5 Jensen DM, Cheng S, Kovacs TOG, Randall G, Jensen ME, Reedy $\mathrm{T}$, et al. A controlled study of ranitidine for the prevention of recurrent haemorrhage from duodenal prevention of recurrent haemorrhage

ulcer. NEngl f Med 1994; 330: 382-6.
6 Hawkey CJ, Hawthorne AB, Hudson N, Cole AT, Mahida YR, Daneshmend TK. Separation of aspirin's Mahida YR, Daneshmend TK. Separation of aspirin's impairment of haemostasis from mucosal ini

7 Bauer RF, Bianchi RG, Casler J, Goldstin B. Comparative mucosal protective properties of misoprostol, cimetidine and sucralfate. Dig Dis Sci 1986; 2: 81-5.

8 Hui WM, Chen BW, Cho CH, Lam SK, Luk CT. The effect of antacid and components of sucralfate on gastric blood flow. Eur f Gastroenterol Hepatol 1991; 2: 169-73.

9 Tarnawski A, Erickson RA. Sucralfate -24 years later current concepts of its protective and therapeutic actions. Eur $\mathcal{F}$ Gastroenterol Hepatol 1991; 3: 795-810.

10 Agrawal NM, Roth S, Graham DY, White RH, Germain B, Brown JA, et al. Misoprostol compared with sucralfate in the prevention of nonsteroidal anti-inflammatory drug induced gastric ulcer. A randomized controlled study. induced gastric ulcer. A randomized
Ann Intern Med 1991; 115: 195-200.

11 Malchow-Moller A, Ranlow PJ. Does sucralfate reduce acetylsalicylic acid induced gastric mucosal bleeding. Scand 7 Gastroenterol 1987; 22: 550-2.

12 Patchett SE, O'Donoghue DP. Mechanisms of intragastric clot lysis. Eur 7 Gastroenterol Hepatol 1991; 3: 633-6.

13 Patchett SE, O'Donoghue DP. Pharmacological manipulation of gastric juice thrombelastographic assessment and implications for treatment of gastrointestina haemorrhage. Gut 1995; 36: 358-62.

14 Tryba M, Zevonou F, Torok M, Zenz M. Prevention of acute stress bleeding with sucralfate, antacids, or cimetidine - a controlled study with pirenzepine as a basic medication. Am f Med 1985; 79: 55-61.
15 Tryba $M$. Sucralfate versus antacids or $\mathrm{H}-2$ antagonists for stress ulcer prophylaxis - a metaanalysis on efficacy and pneumonia rate. Crit Care Med 1991; 19: 942-9.

16 Eddleston JM, Pearson RC, Holland J, Tooth JA, Vohra A, Doran BH. Prospective endoscopic study of stress erosions and ulcers in critically ill adult patients treated erosions and ulcers in critically ill adult patients treated
with either sucralfate or placebo. Crit Care Med 1994; 22: with either

17 Cook DJ, Reeve BK, Guyatt GH, Heyland DK, Griffith LE, Buckingham $\mathrm{L}$, et al. Stress ulcer prophylaxis in critically ill patients - resolving discordant metaanalyses. $f A M A$ 1996; 275: 308-14.

18 Hawkey CJ, Simpson G, Somerville KW. Reduction by enprostil of aspirin induced blood loss from human gastric mucosa. Am f्f Med 1986; 81: 50-4.

19 Hawkey CJ, Somerville KW, Marshall S. Prophylaxis of aspirin induced gastric mucosal bleeding with ranitidine. Aliment Pharmacol Ther 1988; 2: 245-52.

20 Hawthorne AB, Hurst SM, Mahidad YR, Cole AT, Hawkey CJ. Aspirin-induced gastric mucosal damage: Prevention by enteric-coating of aspiring and ramage: prostaglandin synthesis. Br 7 Clin Pharmacol 1991; 33: prostag.

21 Hawkey CJ, Bhaskar NK, Filipowicz B. Synthesis of prostaglandin $\mathrm{E}_{2}$, thromboxane and prostaglandin catabolism in gastritis and gastric ulcer. Gut 1986; 27: 1484-92.

22 Norrman B, Wallen P, Ranby M. Fibrinolysis mediated by tissue plasminogen activation. Eur $\mathcal{F}$ Biochem 1985; 149: 193-200.

23 Benmenachem T, Fogel R, Patel RV, Touchette $M$, Zarowitz BJ, Hadijahic N, et al. Prophylaxis for stress related gastric haemorrhage in the medical intensive care unit. A randomised controlled single blind study. Ann Intern Med 1994; 121: 568-75.

24 Ruizsantana S, Ortiz E, Gonzalez B, Bolanos J, Ruizsantana AJ, Manzano JL. Stress induced gastroduodenal lesions and total parenteral nutrition in critically ill patients - frequency, complications and the value of prophylactic treatment. A prospective randomised study. prophylactic treatment. A prospect

$25 \mathrm{Zach}$ GA Gyr KE, von Alvensleben $\mathrm{E}$, et al. A double blind randomized controlled study to investigate the efficacy of cimetidine given in addition to conventional therapy in the prevention of stress ulceration and haemorrhage in patients with acute spinal injury. Digestion 1984; 29: 214-22.

26 Ruesser P, Gye K, Scheidegger A, et al. Prospective endoscopic study of stress erosions and ulceration in critically ill neurosurgical patients. Current use and effect of acid reducing prophylaxis. Crit Care Med 1990; 18: 270-4.

27 Peura DA. Prophylactic therapy of stress related mucosal damage: Why, which and who and so what? $A m \mathcal{F}$ Gastroenterol 1990; 85: 935-7.

28 Cole AT, Brundell S, Hudson N, Hawthorne AB Mahida YR, Hawkey CJ. Ranitidine, aspirin, food and the Mahida YR, Hawkey CJ. Ranitidine,

29 Ehsanullah RSB, Page MC, Tildesley G, et al. Prevention of gastroduodenal damage induced by non-steroidal antiinflammatory drugs: controlled trial of ranitidine. $B M \mathcal{F}$ 1988; 297: 1017-20

30 Robinson MG, Griffin JW, Bowers J, et al. Effect of ranitidine on gastroduodenal mucosal damage induced by nonsteroidal anti-inflammatory drugs. Dig Dis Sci 1989 ; 34: 424-8.

31 Cole AT, Brundell S, Hudson N, Hawthorne AB, Mahida YR, Hawkey CJ. Ranitidine: differential effects on gastric bleeding and mucosal damage induced by aspirin. Aliment Pharmacol Ther 1992; 6: 707-15. 